\title{
Do storage solutions protect endothelial function of arterialized vein graft in an experimental rat model?
}

\author{
Olivier Fouquet ${ }^{1,2^{*}}$ D , Jean-David Blossier ${ }^{2,3}$, Simon Dang Van ${ }^{1,2}$, Pauline Robert ${ }^{2}$, Agnès Barbelivien², \\ Frédéric Pinaud ${ }^{1,2}$, Patrice Binuani ${ }^{1}$, Maroua Eid ${ }^{1}$, Daniel Henrion ${ }^{2,4}$, Christophe Baufreton ${ }^{1,2+}$ \\ and Laurent Loufrani ${ }^{2,4+}$
}

\begin{abstract}
Background: This study aims to compare the effects of storage solutions commonly used in coronary artery bypass grafting on the vascular reactivity in vein graft interposed in arterial position in syngeneic rats.

Methods: Twenty-seven male Lewis rats were sacrified to sample a vein graft implanted 6 weeks ago into abdominal aorta position. The vein grafts were inferior venae cavae initially pretreated with heparinized saline solution (HS) or autologous heparinized blood (AHB) or our referent solution, GALA. The endothelial functionality, the in situ Reactive Oxygen Species (ROS) levels and the histological characteristics were conducted from segments of arterialized vein graft.

Results: At 6 weeks, graft thrombosis occurred respectively in 22\% of AHB group, $62.5 \%$ in the HS group and $82.5 \%$ in the GALA group. In each group, significative intimal hyperplasia was observed. After 6 weeks, an endothelium-remodeling layer associated with an increase of wall thickness was observed in each group. Endothelium-dependent tone was reduced in the vein graft regardless of the group. No difference was observed concerning the ROS in vein graft between the different groups. In distal aortic sections, ROS levels were increased in HS and GALA groups.

Conclusions: Storage solutions used in this experimental model of vein graft implanted in arterial position cause graft injury and a complete disappearance of vascular reactivity. GALA solution did not reduce intimal risk hyperplasia when the vein graft was exposed to arterial flow in a rat model.
\end{abstract}

Keywords: Coronary artery bypass grafting, Venous graft, Storage solutions, Vascular reactivity

\section{Background}

Ischemic heart disease remains the leading cause of death [1] in developed countries and higher life expectancy increases its incidence. Coronary artery bypass grafting $(C A B G)$ is considered the best treatment in most cases [2]. The success of surgical approach depends on the long-term patency rate of the grafts used. Saphenous vein graft remains the most frequently conduit used in CABG but early occlusion rates were reported ranged from 15 to $26 \%$ at 1 year resulting of vein graft dysfunction [3]. The principle etiologies of early

\footnotetext{
* Correspondence: olfouquet@chu-angers.fr

${ }^{+}$Christophe Baufreton and Laurent Loufrani contributed equally to this work. ${ }^{1}$ Department of Cardiac Surgery, University Hospital of Angers, France, 4 rue Larrey, 49933 CHU Angers Cedex 9, France

${ }^{2}$ Institute MITOVASC CNRS UMR 6015, INSERM 1083, Angers, France

Full list of author information is available at the end of the article
}

postoperative graft failure are technical operative errors, low flow, thrombosis and vasospasm. At mild term a graft failure can appear, and it is histologically characterized by an intimal hyperplasia $(\mathrm{IH})$ which is a proliferation of smooth muscle cells (SMC) and a deposition of extracellular matrix (ECM) in the intima. An atherosclerosis mechanism is observed with a risk of vein graft thrombosis $[4,5]$.

To preserve the SVG quality as well as endothelial cells (EC) viability and functionality, some intraoperative graft storage solutions have been evaluated in-vitro $[6,7]$ and some were developed for vascular conduit preservation $[8,9]$. The GALA solution (Glutathione, Lascorbique acid, L-arginine and glucose; $\mathrm{pH}=7.4$ ), being widely recognized in this purpose; its effects compared to other solutions (saline and autologous blood with 
added heparin) maintained the endothelial function and structural viability of the grafts for 1 to $24 \mathrm{~h}$ of storage [10]. A sub study of the PREVENT IV randomized trial demonstrated that buffered saline solution had lower vein graft failure rate studied by angiography 12 to 18 months after surgery and better clinical outcomes compared to saline or autologous blood solutions [11].

When venous graft is exposed to the arterial blood flow, hemodynamic strengths (shear stress (SS) and cyclic strain (CS)) are applied on the vascular wall. The impact of SS on EC depends on the type flow applied on the venous graft [12]. IH occurs in approximately 50\% of SVG and is characterized by SMC migration from the media to the intima through metalloproteinase (MMPs) activation [13]. Vein graft failure response to hypoxia-reoxygenation injury associates mechanisms of vasospasm, adhesion cascade, ROS (Reactive Oxygen Species) production, platelet aggregation, endothelial cells loss, and shear stress stimulation during the first week [14].

The research concerning storage solutions is in vitro human studies and it is clearly accepted that they have a fundamental role in the early preservation of the endothelium of the vein graft [15]. However, when the venous graft was exposed to arterial shear-stress and cyclic strain, smooth muscle cells change their phenotype from a contractile to a secretory stage [16]. Physiologically, venous endothelium produces small amount of NO while in arterial position, the production decreases. The storage solution should maintain a physiological $\mathrm{pH}$ and support endothelial NO production by provision of an eNOS substrate [17]. A lot of intraoperative vein graft preservation solutions were studied but we focused three of them according to our clinical practice and following the results of experimental study [10]. The purpose of this study was to evaluate if autologous heparinized blood, heparinized saline serum and GALA considered as our referent solution could have a protective effect on an arterialized vein graft in a rat model.

\section{Methods}

Figure 1 shows the flowchart of the different steps.

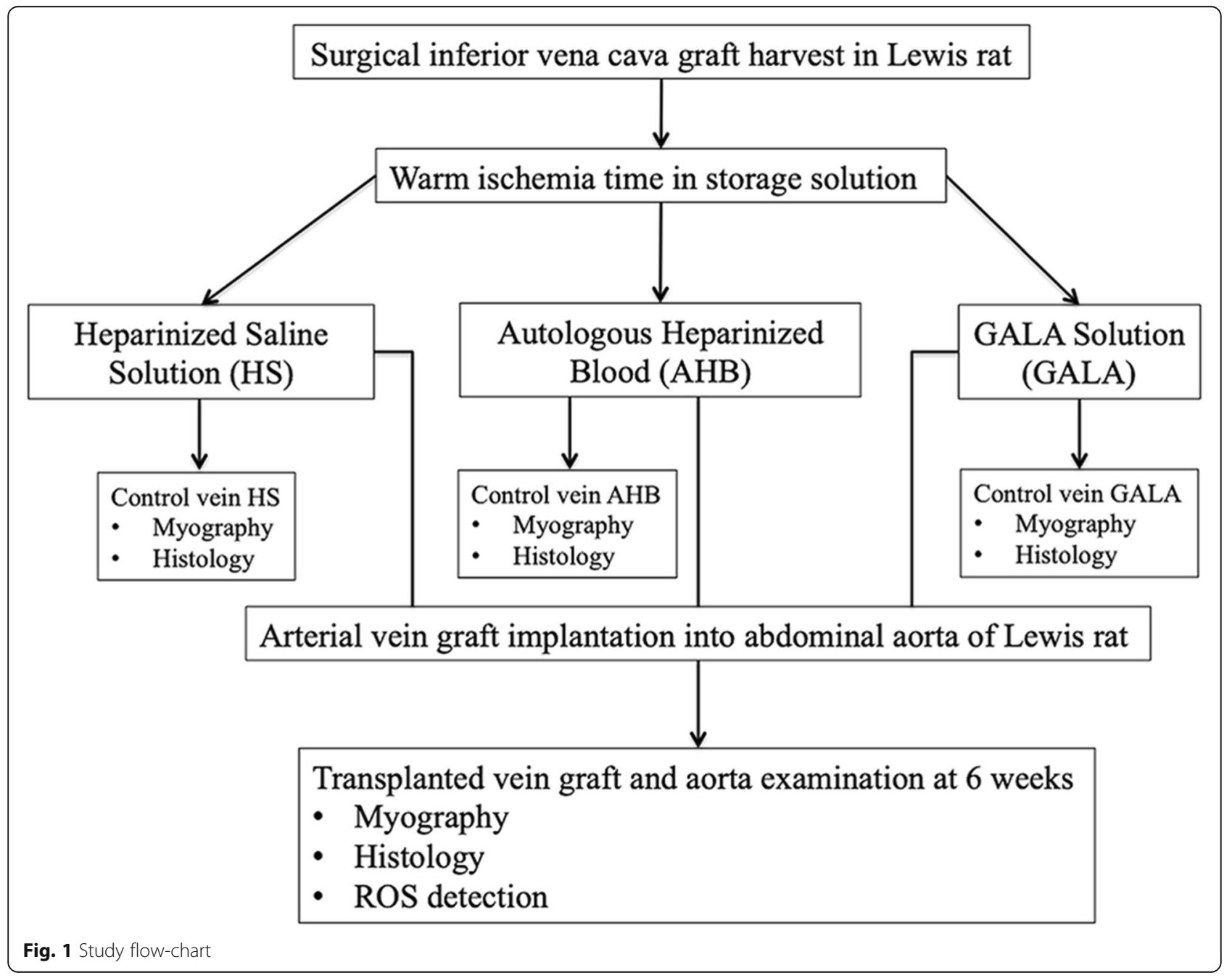




\section{Preservation solution}

The inferior venae cava grafts were randomly stored in the different preservation solutions at room temperature $\left(20^{\circ} \mathrm{C}\right)$ before implantation. Three different storage solutions were used for the ex-vivo preservation of explanted veins. Vein grafts were stored in one of the following solutions: autologous heparinized $(40 \mathrm{UI} / \mathrm{ml}$ heparin choay) blood (AHB), $0.9 \%$ sodium chloride heparinized (40 UI/ml heparin choay) serum (HS); GALA solution (gluthion, ascorbic acid, L-arginine) prepared at the hospital pharmacy which constitutes in our institution the referent storage solution used in CABG for vein grafts. GALA solution was composed of physiologic salt solution to which was added: $0.02 \mathrm{ml}$ magnesium sulfate, $1.785 \mathrm{mg}$ potassium hydrogenophosphate, $0.03 \mathrm{ml}$ magnesium chloride, $0.042 \mathrm{ml}$ calcium chloride, $0.08 \mathrm{ml}$ potassium chloride, $5000 \mathrm{UI} / \mathrm{ml}$ heparin choay, L-ascorbic acid $(1 \mathrm{~g} / 500 \mathrm{ml}), 0.6 \mathrm{ml}$ glucose $5 \%, 0.75 \mathrm{ml}$ sodium bicarbonate, $1.2 \mathrm{ml}$ sodium chloride, $1.5 \mathrm{ml} \mathrm{L}$-arginine as a substrate for endothelial nitric oxide synthetase (eNOS) and $2.7 \mathrm{ml}$ glutathione. The inferior vena cava segments were collected from 27 donor rats.

\section{Animals}

Inbred male LEWIS (Albino rat, a/a, B/B, $\mathrm{Tyr}^{\mathrm{c}} / \mathrm{Tyr}^{\mathrm{c}}, \mathrm{h} / \mathrm{h}-$ MHC: RT1') rats weighting $337 \pm 17 \mathrm{~g}$ and aged $12.8 \pm$ 0.75 weeks (JANVIER LABS, Le Genest Saint Isle, France) were housed in a regulatory pet. No exogenous immunosuppressive drug therapy was employed. All procedures were performed according to the guidelines of the Institutional Animal Care and approved by the Ministère Français de l'enseignement Supérieur et de la Recherche (authorization number December 2014: 000375.01).

\section{Surgical harvest and implantation of the vein graft}

Twenty-seven donor rats were anaesthetized (isoflurane $5 \%$ ) and pretreated with buprenorphine (Temgesic; 0.1 $\mathrm{ml} / 100 \mathrm{~g} \mathrm{S.C}$ ). A large incision through the abdominal wall allowed to expose the inferior vena cava and the abdominal aorta. The different branches of the vein were ligatured with 8-0 monofilament Prolene ${ }^{\circ}$. The donor rats were sacrificed in a $\mathrm{CO} 2$ chamber. The inferior vena cava was stored in a preservation solution ( 9 in AHB, 9 in HS and 9 in GALA) previously described. Each vein was carefully flushed with the storage solution. After storage in one of the preservation solutions and before arterial implantation, a segment of the vena cava was sampled then stored in PSS for myography and corresponding to the control vein group (AHB control vein, HS control vein and GALA control vein).

Twenty-seven recipient rats were anaesthetized and pretreated as described. The abdominal aorta was exposed, isolated from the adjacent inferior vena cava and controlled with a loop between the renal arteries and the aorta bifurcation. The aorta was clamped, and an arterial segment was removed. Heparin injection (300 UI/kg) was performed during the procedure. The vein graft was interposed into the recipient's abdominal aorta, an endto-end anastomosis was then established between the donor and the recipient vessels, respectively, using a running 9-0 monofilament suture Prolene ${ }^{\circ}$ at $\times 10 \mathrm{mag}$ nification (Fig. 2). At the end of this procedure, the clamps were removed, the patency of transplanted graft was confirmed and blood supply to the pelvis and lower extremities was restored. Rats were placed in an incubator at $29^{\circ} \mathrm{C}$ for $20 \mathrm{~min}$ until fully awake and monitored for signs of lower limb ischemia, hemorrhage and pain. Antibiotics were administered for 7 days (Bactrim $2.5 \mathrm{ml}$ per liter of drinking water). Buprenorphine from 0.067 to $0.33 \mathrm{ml}$ per $100 \mathrm{~g}$ was administered in case of mild, moderate or severe pain (pain scale in rats according to the guidelines of the Institutional Animal Care) The same cardiac surgeon performed all procedures.

\section{Transplanted vein graft examination}

At 6 weeks after transplantation, under anesthesia, the abdomen was exposed, previously implanted vein grafts with a proximal and distal segments of the aorta were removed and subsequently divided into five segments of commensurate length: two segments (proximal aorta and vein graft) were stored in a $10 \mathrm{ml}$ organ bath containing a physiologic salt solution (PSS) for myography and three segments (proximal aorta, distal aorta and vein graft) were cooled in liquid nitrogen and stored at $80^{\circ} \mathrm{C}$ for histology and immunohistochemistry.

\section{Vascular reactivity}

Myography: for each sacrificed recipient rat, 3 fresh segments of distal aorta, vein graft and control vein stored in PSS were analyzed. At day+1, the fresh segments were mounted on a wire-myograph (DMT, Aarhens, DK) as previously described [18]. Briefly, 2 tungsten wires $(25 \mu \mathrm{m}$ diameter) were inserted in the lumen of the grafts and connected to a force transducer and a micrometer, respectively. Vascular grafts were bathed in the PSS described above. A wall tension, equivalent to the intra-arterial tension $(20 \mathrm{mN}$ for aortic segment and $5 \mathrm{mN}$ for control vein and vein graft segments), was applied corresponding or equivalent to arterial blood pressure at $90 \mathrm{mmHg}$. Vessels were allowed to stabilize for $20 \mathrm{~min}$. Contractility was assessed with phenylephrine (PE 10-6 M). Actylcholine (Ach 10-6 M) induced relaxation was then obtained after phenylephrine-induced preconstriction (50\% of maximal contraction). Vascular response to PE (from 10 to $9 \mathrm{M}$ to $10-5 \mathrm{M}$ ), Ach (from 10 to $9 \mathrm{M}$ to $10-5 \mathrm{M}$ ) and SNP (Sodium Nitroprusside) (from 10 to $9 \mathrm{M}$ to $10-5 \mathrm{M}$ ) were studied. 


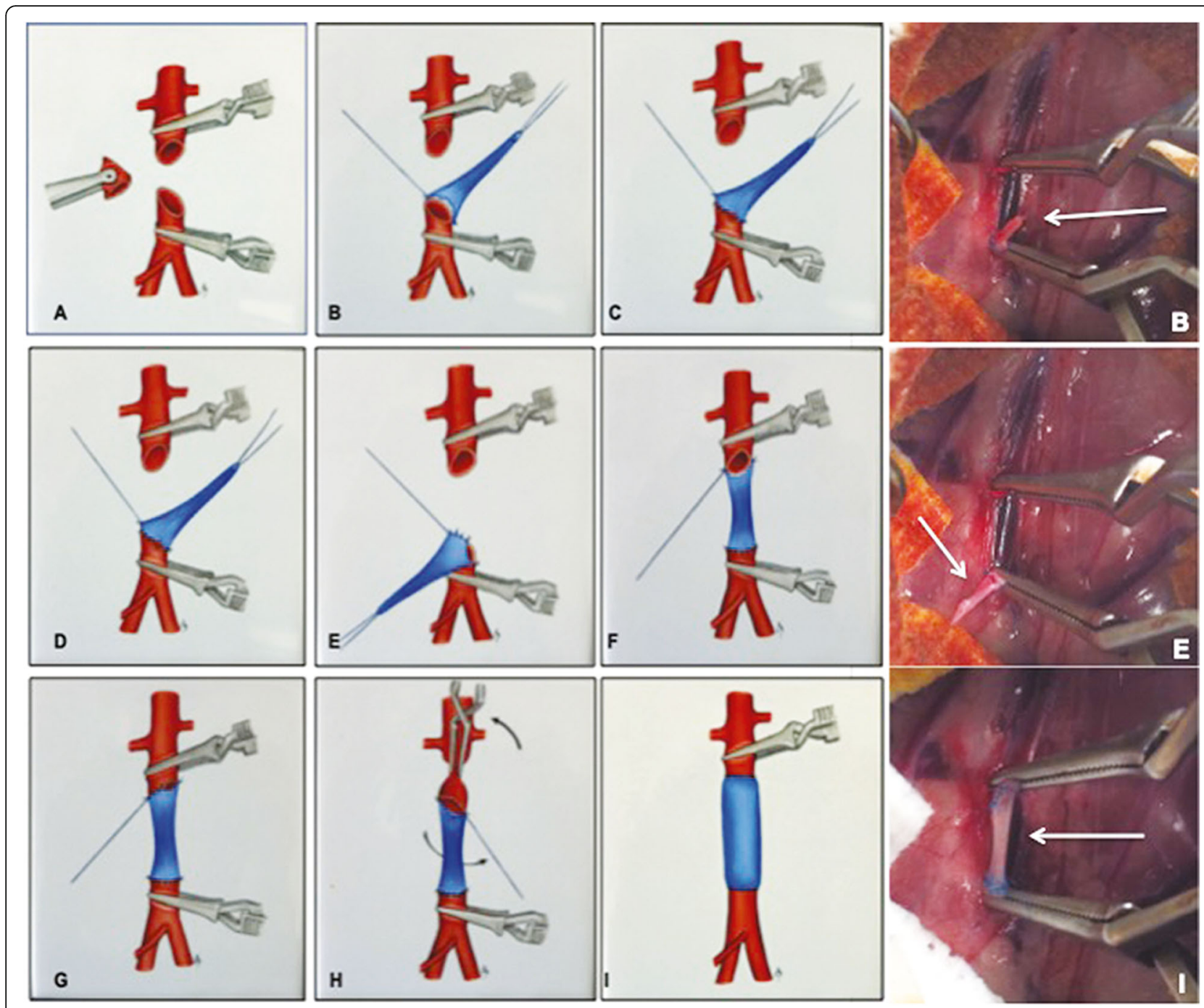

Fig. 2 After clamping the abdominal aorta below renal arteries, an arterial segment was removed (a). The vein graft was interposed into the recipient aorta starting with the distal suture $(\mathbf{b})$. The first interrupted suture concerned the posterior wall of the graft (c) then the anterior wall was better exposed (d). Pulling down from the graft exposed the posterior suture (e). The proximal anastomosis was performed with posterior interrupted sututre $(\mathbf{f})$ then the anterior suture $(\mathbf{g})$. Torsion of the graft was performed to expose the posterior wall and to finalize the suture $(\mathbf{h})$. The clamps were removed and the patency of the graft was confirmed by recoloring the lower extremities (i)

\section{Histology}

Vascular segments were embedded in paraffin and cooled at $-80^{\circ} \mathrm{C}$. Sections $(7 \mu \mathrm{m}$ thickness $)$ were obtained from the fixed arterial segments and stained with orcein to visualize elastic fibers. External diameter, lumen diameter, and media thickness were determined after images acquisition (Olympus T100 microscope, Sony Camera) and analyzed using the Histolab Software (Microvision, Paris, France) for cross-sectional area (CSA) calculation as previously described [19].

\section{Detection of reactive oxygen species detection using confocal microscopy}

Dihydroethidium staining (DHE, Sigma-Aldrich) was used to evaluate the in-situ levels of superoxide anions
$\left(\mathrm{O}_{2}^{-}\right)$[20]. DHE penetrates cells and is oxidized by superoxide $\left(\mathrm{O}_{2}{ }^{-}\right)$into fluorescent products that are trapped by intercalation into the DNA. Sections were incubated with DHE $(1 \mu \mathrm{mol} / \mathrm{L})$ in phosphate-buffered solution (PBS) and DAPI (4', $6^{\prime}$-diamidino-2-phénulindoleMolecular probes, Invitrogen) for nuclear cells at $37^{\circ} \mathrm{C}$ for $30 \mathrm{~min}$ in a humidified chamber protected from light. Fluorescent images of ethidium bromide were obtained using a confocal microscope (Nikon) and quantified with the Image $(\mathrm{NIH})$ software. The different studied sections were vein graft and distal aorta samples.

\section{Statistical analysis}

Data were reported as mean \pm standard error the mean unless indicated otherwise. Considering the sample size, 
non-parametric tests (t-test or Mann-Whitney test) were conducted to assess the statistically significant of each experiment using Graphpad Prism software (La Jolla, Calif). $P$ value of $\leq .05$ was considered statically significant.

Sample size: based on a previous study [21], and to show a difference between the three groups at a power of $90 \%$ with a significance level of $5 \%$ concerning vascular reactivity and inflammatory response, a sample size of 27 rats was required for this experimental study (9 per group).

\section{Results}

\section{Surgery and occlusion rate of the venous graft}

The mean duration of venous storage and duration of surgery, the weight gain during the follow-up were presented in the Table 1 . At 6 weeks, the mortality was $0 / 9$ in the HS group, $1 / 9$ in the AHB group (bleeding, $n=1$ ) and $3 / 9$ in the GALA group (bleeding, $n=2$; mesenteric ischemia, $\mathrm{n}=1$ ).

Among rats alive, thrombosis occurred respectively in $2 / 9(22 \%)$ grafts of AHB group, 5/8 (62.5\%) in the HS group and 5/6 (83.3\%) in the GALA group (Fig. 3). The suture analysis showed no proximal nor distal anastomoses stenosis.

\section{Histology}

The wall thickness of control vein was $17.75 \pm 3 \mu \mathrm{m}$ in the HS group, $16.3 \pm 4 \mu \mathrm{m}$ in the AHB group and $17.3 \pm$ $5 \mu \mathrm{m}$ in the GALA group (0.7). The wall thickness of vein grafts was $105 \pm 32 \mu \mathrm{m}$ ( $+83.1 \%$ compared with wall thickness of control vein) in the HS group, $101 \pm 25 \mu \mathrm{m}$ $(+83.9 \%)$ in the AHB group and $107 \pm 31 \mu \mathrm{m}(+83.8 \%)$ in the GALA group (0.8). The orcein staining showed an important intimal hyperplasia in the vein graft with a disappearance of endothelium layer and a structural media failure regardless the preservation solution used (Fig. 4). The distal aorta retains its histological architecture in each group. An intraluminal fibrosis was observed in the occluded grafts (Fig. 3).

\section{Myography}

Because of the small number of permeable vein grafts at 6 weeks, the analysis concerned the average of the three preservation solutions groups.

Phenylephrine induced a significant contraction in the aorta $\left(3.10^{-8} \mu \mathrm{mol} / \mathrm{L}\right)$, about $50 \%$ in the control vein (from $10^{-6}$ to $3 \cdot 10^{-6} \mu \mathrm{mol} / \mathrm{L}$ ). No contraction was observed on the vein graft except for high doses of phenylephrine (from $10^{-6}$ to $10^{-5} \mu \mathrm{mol} / \mathrm{L}$ ).

Acetylcholine did not induce dilatation neither in the control vein nor the aorta and the vein graft. Sodium nitroprusside induced a significant dilatation in the control vein compared to the vein graft $(p<0.01)$ (Fig. 5). A dilatation was observed in the aorta for high dose of sodium nitroprusside (from $10^{-7}$ to $10^{-5} \mu \mathrm{mol} / \mathrm{L}$ ).

\section{ROS detection}

In venous graft sections, there was no difference concerning the superoxide formation evaluated by ethidium bromide-enhanced fluorescence (Fig. 6a). Moreover, in distal aorta sections, superoxide anion levels were significantly higher in HS group than AHB and GALA groups (Fig. 6b).

\section{Discussion}

Vein graft failure is the result of a complex mechanism associating endothelial injury which can occur from the surgical harvesting, intimal hyperplasia and atherosclerosis [22]. The main role of storage solutions is to preserve the endothelium of graft conduit and their actions run from storage period to arterial implantation [15].

\section{Vein graft analysis at 6 weeks}

- Saphenous vein graft (SVG) represents an autologous transplantation, as it is explanted, preserved in storage solution into a cup at room temperature and then implanted in arterial system. In clinical practice, the duration of vein graft storage corresponding to the warm ischemia tissue was difficult to evaluate because no data are published. Some surgeons do not store SVG before creating the anastomoses and develop the concept of "no-touch technique" with excellent graft patency [23]. In contrast to what is done for solid organs destined for allotransplantation, where different preservation solutions were developed such as University of Wisconsin solution for pancreas or Celsior solution for heart, the normal saline solution was the first storage solution for SVG. O'Connel et al. demonstrated that $2 \mathrm{~h}$ of saline infusion produced an $\mathrm{IH}$ [24]. Saline solution has negative effects on the endothelial layers and therefore may compromise graft patency [25]. However, different in-vitro studies cannot conclude on the superiority of autologous

Table 1 Surgical data

\begin{tabular}{llll}
\hline & Heparinized Saline solution & Autologous Heparinized & GALA solution \\
& BS $(n=9)$ & $106 \pm 57$ & $88 \pm 57$ \\
\hline Duration of venous storage (min) & $91 \pm 56$ & $63 \pm 10$ & $67 \pm 11$ \\
Duration of venous transplantation (min) & $67 \pm 11$ & $79 \pm 22$ & $69 \pm 21$ \\
Weight gain during follow-up (gr) & $73 \pm 24$ & $(n=9)$ & (1) \\
\hline
\end{tabular}



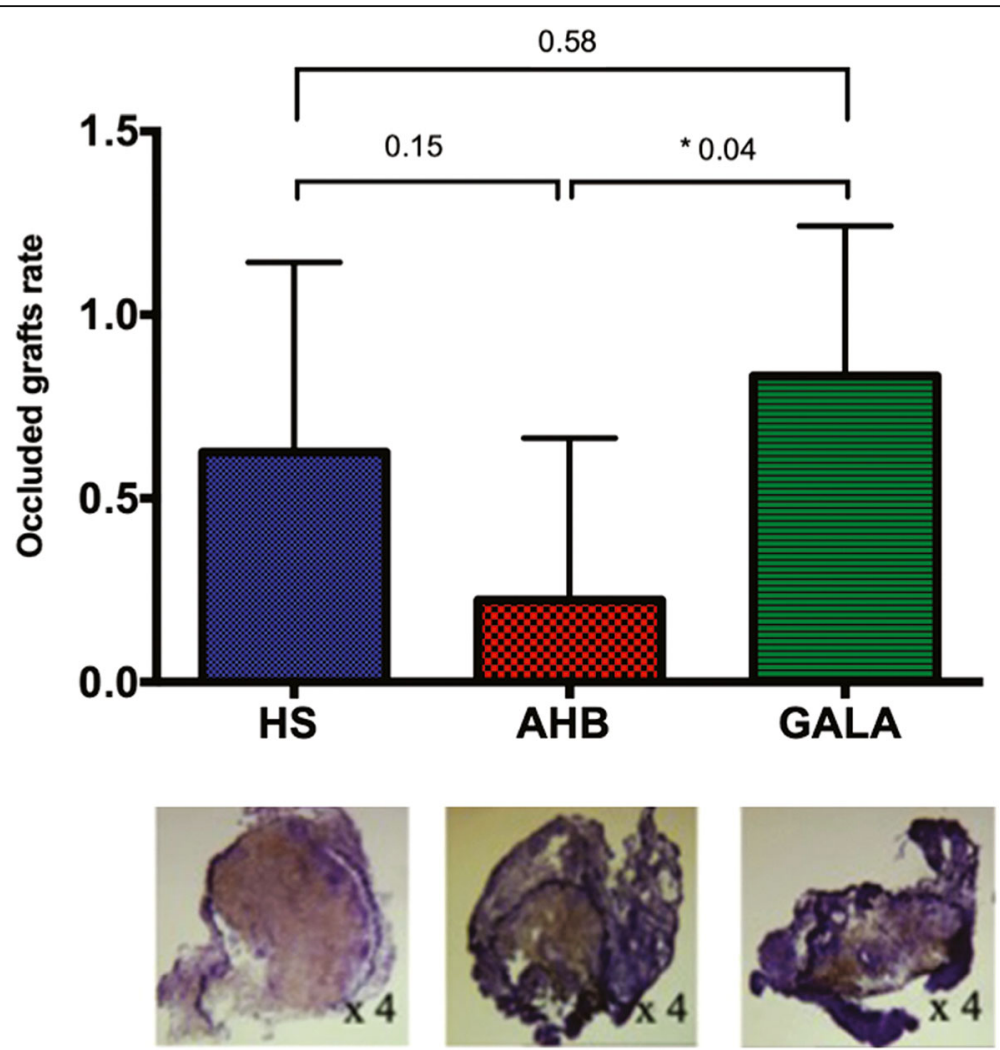

Fig. 3 A non-parametric test was used to compare the different groups. Occluded grafts rate was higher in the GALA group than HS group ( $p=$ $0.04)$ and AHB group $(p=0.58)$

whole blood, alternatives solutions such as storage solutions like Tiprotec $^{\mathrm{Tm}}$ or Somaluthion ${ }^{\mathrm{Tw}}$ remain the subject of further clinical trial [25]. Other study showed that autologous whole blood had some clear advantages compared to saline solution, this difference does not persist post-arterialization [26]. In the present study, the duration of vein storage in the different solution was high as to allow preparation of the recipient rat following vein graft harvesting but no relation was found between storage duration and importance of IH. Thatte et al. showed that duration of storage time in GALA solution (from $60 \mathrm{~min}$ to $1440 \mathrm{~min}$ ) did not alter smooth muscle or endothelial cell function [10]. None of the storage solutions used in this study has reduced the intimal hyperplasia. In fact, we observed a significant increase of the wall thickness and histological signs of fibrosis.

- Among the occluded veins, only an important IH could explain the vein graft occlusion. In order to obtain an arterialized vein graft, we analyzed the conduit at 6 weeks when the IH started its process. Similar results were observed in the study published by Wong et al. who performed arteriovenous fistula in a murine model and then collected for analysis at 7,14 and 28 days postoperatively [27]. They found significant changes in the intima at 7 days, a significant hyperplasia was observed at 14 days and the patency rates at 28 days were $50 \%$. Sun et al. investigated the efficacy of oral administration of hydrogen-rich water $(\mathrm{HW})$ for prevention of intimal hyperplasia concerning inferior vena cava placed as an interposition graft in the abdominal aorta. Six weeks after bypass procedure, all vein grafts presented SMC and collagen deposits, macrophage infiltration but significantly less in the rats that consumed HW [28]. In our study, the rate of occluded vein grafts among them was greater in the GALA group than AHB and saline solution groups. GALA solution is based on a physiological salt solution and contains glutathione and L-ascorbic acid, antioxidant and arginine, a substrate for NOS (Nitric Oxide Synthetase) in EC to protect the endothelium against ischemic injury during storage. The analysis of GALA effects on EC showed a protecting endothelial structure and function [10]. According to our results, we cannot conclude that GALA solution protects the endothelial layer when the vein graft was arterialized in this rat model. These results should be interpreted with caution if we extrapolated them in human. The occluded vein graft rate at 6 weeks is low after coronary bypass but probably storage solutions did not limit vascular remodeling during the chronic intimal hyperplasia (stage III), their benefits intervening during the first weeks. 


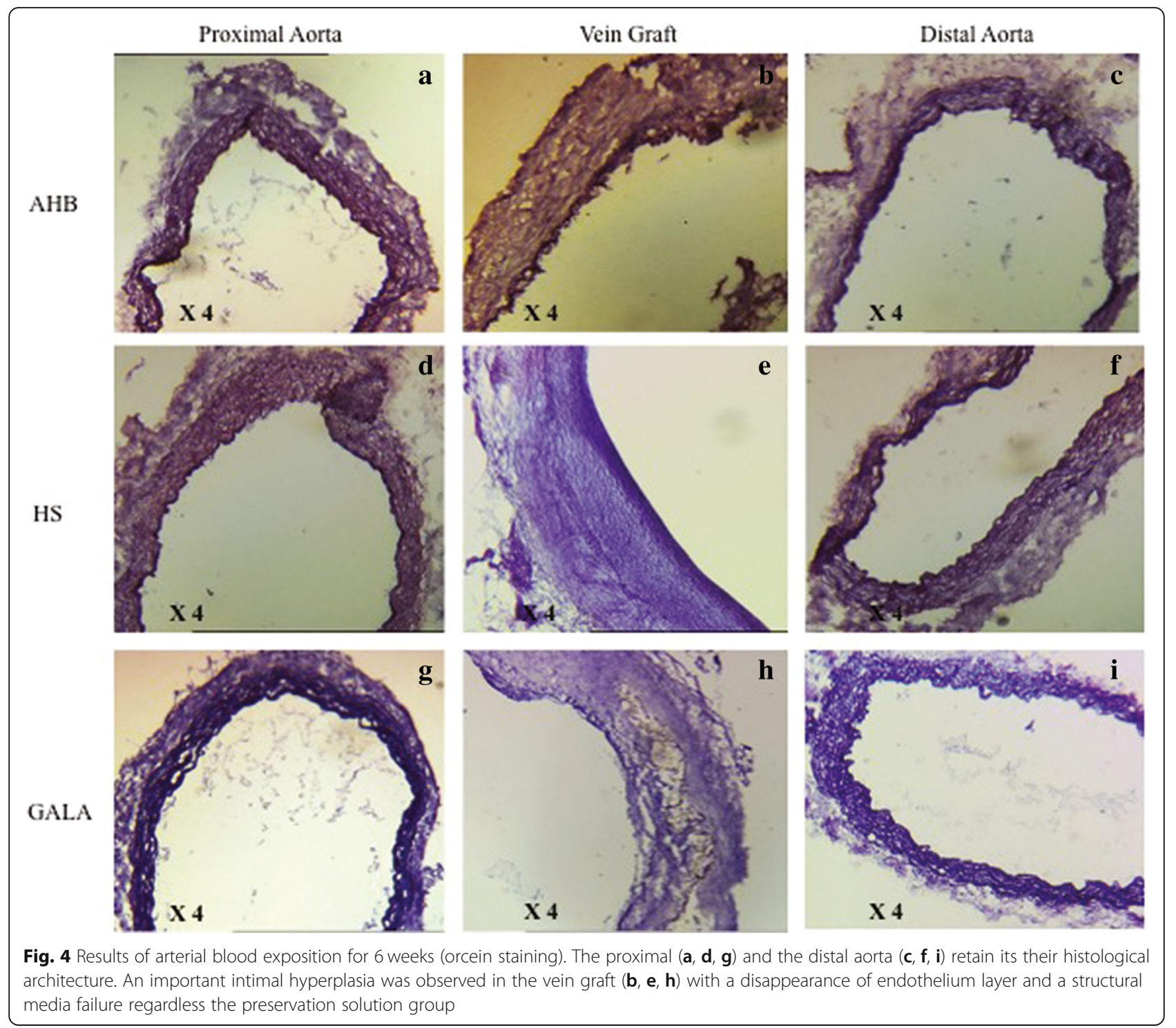

Haime $M$ et al. compared the impact of intraoperative preservation of SVG in GALA solution (Duragraft ${ }^{\circ}$ ) versus heparinized saline on vein-graft failure related outcomes after CABG in 2436 consecutive patients. In this retrospective study, the intraoperative treatment of SVGs with Duragraft was associated with a lower risk of nonfatal myocardial infarction, revascularization [29]. However, these encouraging results must be interpreted with caution and only a well-constructed randomized study will answer the real question "which solution best preserves endothelial integrity from the vein harvesting to the arterial implantation" [17].

Many studies showed that intimal hyperplasia is an adaptive mechanism following arterialization of the vein and is unlikely linked to vein graft thrombosis [30]. Arterialization of a vein appears when the graft is exposed to arterial flow. Contractile SMC become secretory and proliferative [16]. EC cannot produce NO and endothelial layer damage produces growth factors and proinflammatory cytokines (IL-6, IL-8) [31]. This process promotes leukocytes recruitment and thrombin formation [32].

- In the present study, regardless of the storage solution, no endothelium-dependent dilatation was observed when the vein grafts were mounted on a wire-myograph attesting to endothelial injury. The same findings were showed in the control vein and aorta groups. However, the SMC layer viability was observed in the control vein group, the preservation solutions maintained the SMC functionality from 88 to $106 \mathrm{~min}$ of storage.

The implication of the shear stress in vascular biology and inflammation was described by Touys et al. [33]. All vascular cell types produce reactive oxygen species (ROS) that regulate vascular function by modulating cell 


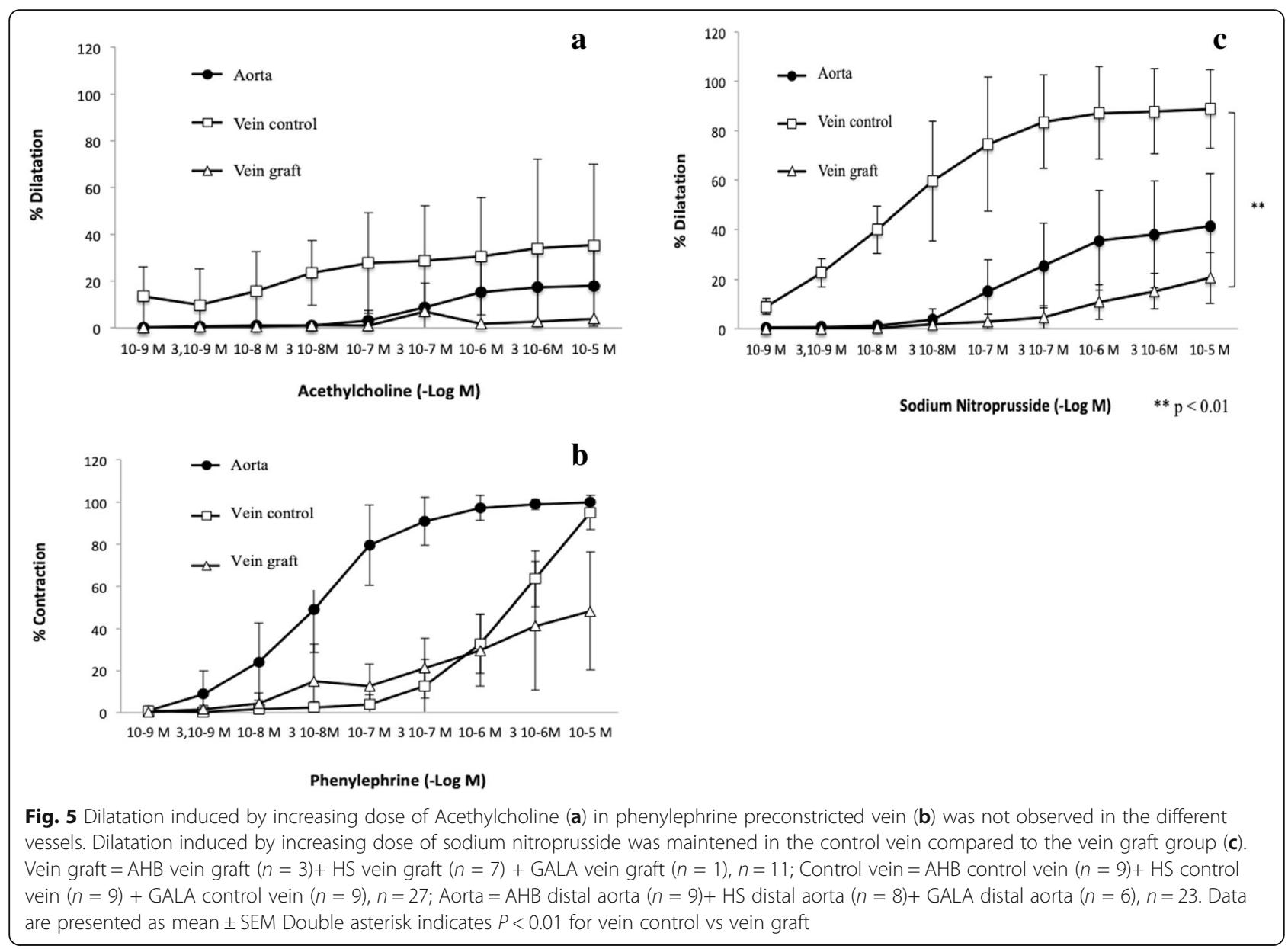

growth, apoptosis, migration, inflammation and extracellular matrix protein production. Oxidative stress and associated oxidative damage are mediators of vascular injury and inflammation and constitute the first steps of atherosclerosis development [13]. In our study, we observed an important oxidative stress in the different vein graft segments analyzed. The inflammatory response into the vein wall due to shear stress was also observed in arterial samples explaining the vascular function damage. These results should be interpreted with caution because of the small number of permeable vessels at 6 weeks. In the presence of high levels of sodium nitroprusside, a dilatation was observed in the control vein group. Saad Enouri et al. studied characteristics of myogenic reactivity in isolated rat mesenteric veins. The integrity of the endothelium was assessed by a dilator response to acetylcholine in phenylephrine-preconstricted veins. The veins were able to develop significant myogenic tone that appears greater over the low-to-intermediate pressure ranges, but mesenteric veins did not demonstrate myogenic responses unlike mesenteric arteries [34]. In our study, the control vein presented an endothelium-dependent relaxation injury with a preservation of smooth muscle cell (SMC) activity (endothelium-independent relaxation) while the vein graft was no vascular reactivity because of endothelial injury but conserved a low relaxation mediated by SMC for high dose of sodium nitroprusside.

\section{Focus of the model}

Models of venous grafting in the arterial position have been used to improve the patency of grafts in humans $[35,36]$, which is especially relevant in CABG. Goldman et al. [37] reported saphenous vein graft patency of $60 \%$ or more at 10 years postoperatively in humans. Animal models are useful to analyze the pathology of vein graft disease and to test therapeutic strategies in vivo [38]. In large animals such as pigs and dogs, the model consists of an interposition of saphenous and jugular veins into common carotid artery. Wan et al. reported rate patency at 4 weeks [39] with saphenous vein-common carotid artery interposition model in large white swine. In rats, different models of inferior vena cava into abdominal aorta interposition have been described as superficial epigastria vein into femoral artery interposition or ileolumbar vein into the abdominal aorta interposition [28]. 


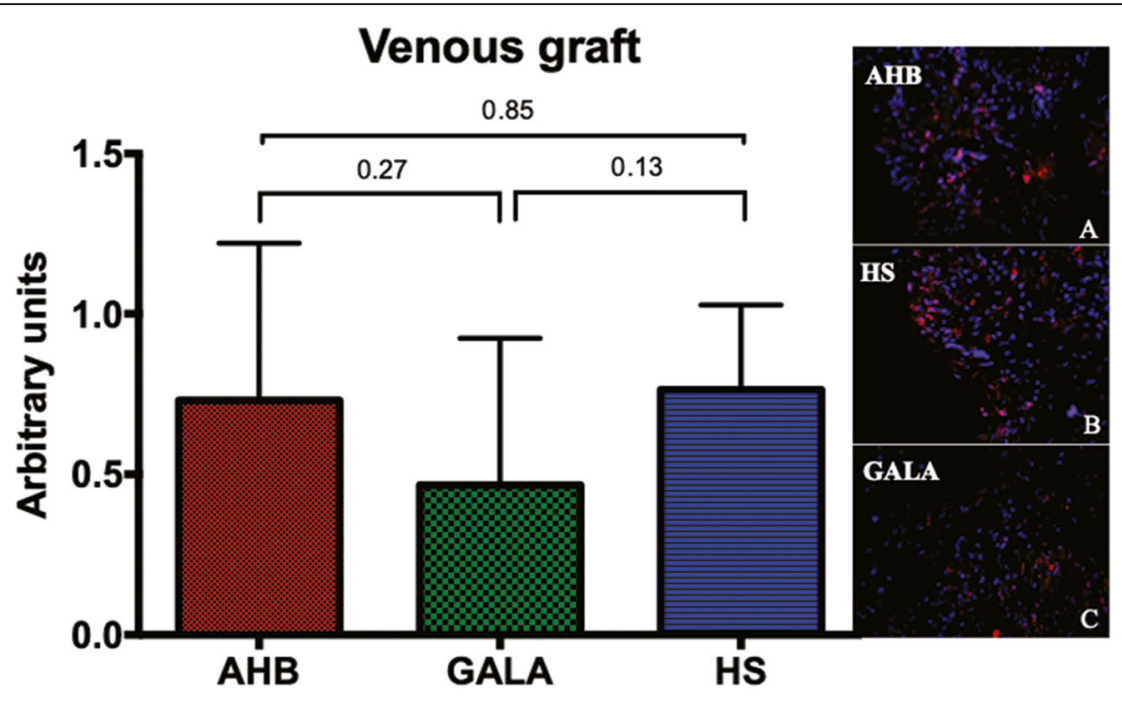

a

Distal Aorta

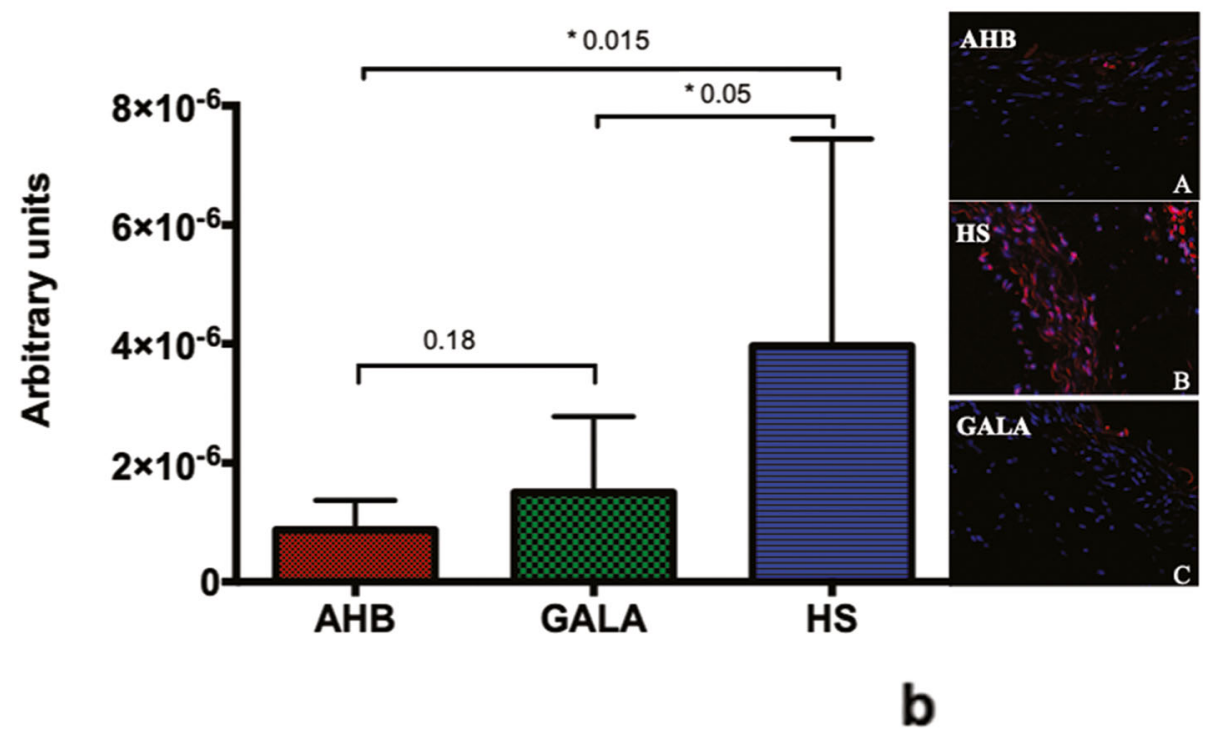

Fig. 6 Superoxide production in the different groups is shown in the bar graphs for venous grafts section (a) and for distal aorta sections (b). Fluorescent images of ethidium bromide (DHE) are colored in red and DAPI in blue

In the surgical model proposed by Sun et al., the vein graft was interposed into the recipient's abdominal aorta using microsurgical techniques in a latero-terminal configuration, and the aorta of the recipients was then ligated between the two anastomoses [28] while we developed an end-to-end anastomosis technique aligning vein and arterial endothelial cells in direction of arterial blood flow, therefore minimizing the effects of shear stress. Vein graft failure is characterized by an inflammatory response with leukocytes recruitment from circulating blood cells as we did not observe on the aorta segments. Like saphenous vein graft during CABG, our vein graft was submitted to a systolic flow. The vena cava was harvested using state-of-the-art and optimal handling techniques (same surgeon, a traumatic surgical technique, avoiding excessive handling and distortion) in order to reduce traumatic damage to the endothelium layer, which is the first step of the graft failure. The main difficulty in vein graft transplantation was the vein wall's thickness. In fact, the texture of the vein issued from its storage solution makes the wall extremely fine. 


\section{Limitations of the study}

The high number of occluded vein grafts reduced the possibilities of analysis. Moreover, intermediate analysis of the vein grafts should have been performed in order to explain the mechanisms of vascular inflammation in relation of each group. Due to the small number of vein grafts sections we combined data from all storage solution groups in order to compare vascular reactivity to each solution.

\section{Conclusion}

The composition of preservation solutions influences vein graft endothelial structural and functional integrity from early graft failure. However, the next crucial step will be conducted randomized clinical trial to compare storage solutions and long-term clinical outcomes because our experimental study show that some solutions do not protect the vein graft from intimal hyperplasia and thrombosis formation during the arterialization stage in this experimental study.

\section{Abbreviations}

CABG: Coronary artery bypass grafting; CS: Cyclic strain; EC: Endothelial cells; ECM: Extracellular matrix; HW: Hydrogen-rich water; IH: Intimal hyperplasia; NOS: Nitric oxide synthetase; SMC: Smooth muscle cells; SS: Shear stress; SVG: Saphenous vein graft

\section{Acknowledgments}

No

\section{Authors' contributions}

OF, substantial contributions to the conception and design of the work, and draft the work; And JDB performed all surgical procedures and the acquisition, interpretation of data for the work; And PR, AB performed ROS detection practice; And SDV, FP, PB, ME, DH, CB, LL, revising it critically for important intellectual content. All authors read and approved the manuscript.

\section{Funding}

This work was supported by a research grant from the French Society of Thoracic and CardioVascular Surgery (SFCTCV: Société Française de Chirurgie Thoracique et Cardio-Vasculaire, Paris, France).

\section{Availability of data and materials}

The datasets used and/or analyzed during this study available from the corresponding author on reasonable request.

\section{Ethics approval}

This study was conducted in accordance with the guidelines of the institutional animal care of the University of Angers, France. This study was conducted with approval from the "Ministère Français de l'enseignement Supérieur et de la Recherche" (authorization number December 2014: 000375.01).

\section{Consent for publication}

Obtained from the participants.

\section{Competing interests}

The authors declare that they have no competing interests.

\section{Author details}

${ }^{1}$ Department of Cardiac Surgery, University Hospital of Angers, France, 4 rue Larrey, 49933 CHU Angers Cedex 9, France. ${ }^{2}$ Institute MITOVASC CNRS UMR 6015, INSERM 1083, Angers, France. ${ }^{3}$ Department of Cardiac Surgery, CHU Dupuytren, Limoges, France. ${ }^{4}$ University Hospital of Angers, Angers, France.
Received: 24 September 2019 Accepted: 30 January 2020

Published online: 10 February 2020

\section{References}

1. Timmis A, Townsend N, Gale C, Grobbee R, Maniadakis N, Flather M, et al. European Society of Cardiology: Cardiovascular Disease Statistic 2017. Eur Heart J. 2018;39(7):508-79.

2. 2018 ESC/EACTS Guidelines on myocardial revascularization. Eur Heart J. 2018;35(37):2541-619.

3. Thatte $H$, Khuri S. The coronary artery bypass conduit: intraoperative endothelial injury and its implication on graft patency. Ann Thorac Surg. 2001;72:S2245-52.

4. Davies MG, Hagen PO. Pathophysiology of vein graft failure: a review. Eur J Vasc Endovasc Surg. 1995;9:7-18.

5. Gaudino M, Antoniades C, Benedetto U, Deb S, Di Franco A, Di Giammarco $\mathrm{G}$, et al. Mechanisms, consequences, and prevention of coronary graft failure. Circulation. 2017;136(18):1749-64.

6. Wise ES, Hocking KM, Eagle S, Absi T, Komalavilas P, Cheung-Flynn J, et al. Preservation solution impacts physiologic function and cellular viability of human saphenous vein graft. Surgery. 2015;158:537-46.

7. Tsakok M, Montgomery-Taylor S, Tsakok T. Storage of saphenous vein grafts prior to coronary artery bypass grafting: is autologous whole blood more effective than saline in preserving graft function? Interact Cardiovasc Thorac Surg. 2012;15(4):720-5.

8. Wilbring M, Tugtekin SM, Zatschler B, Ebner A, Reichenspurner H, Matschke $K$, et al. Even short-time storage in physiological saline solution impairs endothelial vascular function of saphenous vein grafts. Eur J Cardiothorac Surg. 2011;40(4):811-5.

9. Kay MD, Hosgood SA, Harper SJ, Bagul A, Waller HL, Nicholson ML. Normothermic versus hypothermic ex vivo flush using a novel phosphate-free preservation solution (AQIX) in porcine kidneys. J Surg Res. 2011;171:275-82.

10. Thatte HS, Biswas KS, Najjar SF, Birjiniuk V, Crittenden MD, Michel T, Khuri SF Multi-photon microscopic evaluation of saphenous vein endothelium and its preservation with a new solution. GALA Ann Thorac Surg. 2003;75(4): 1145-52 discussion 1152.

11. Harskamp RE, Alexander JH, Schulte PJ, Brophy CM, Mack MJ, Peterson ED, et al. Vein graft preservation solutions, patency, and outcomes after coronary artery bypass graft surgery: follow-up from the PREVENT IV randomized clinical trial. JAMA Surg. 2014;149(8):798-805.

12. Shigematsu K, Yasuhara H, Shigematsu H, Muto T. Direct and indirect effects of pulsatile shear stress on the smooth muscle cell. Int Angiol. 2000;19(1):39-46.

13. Ward AO, Caputo M, Angelini GD, George SJ, Zakkar M. Activation and inflammation of the venous endothelium in vein graft disease. Atherosclerosis. 2017;265:266-74.

14. Osgood MJ, Hocking KM, Voskresensky IV, Li FD, Komalavilas P, CheungFlynn J, Brophy CM. Surgical vein graft preparation promotes cellular dysfunction, oxydative stress, and intimal hyperplasia in human saphenous vein. J Vasc Surg. 60(2014):202-11.

15. Ben Ali W, Bouhout I, Perrault LP. The effect of storage solutions, gene therapy, and antiprolifertive agents on endothelial function and saphenous vein graft patency. J Card Surg. 2018;33(5):235-42.

16. Cheng J, Du J. Mechanical stretch simulates proliferation of venous smooth muscle cells through activation of the insulin-like growth factor-1 receptor. Arterioscler Thromb Vasc Biol. 2007;27(8):1744-51.

17. Woodward LC, Antoniades C, Taggart DP. Intraoperative vein graft preservation: what is the solution? Ann Thorac Surg. 2016;102(5):1736-46.

18. Henrion D, Laher I, Bevan BA. Intraluminal flow increases vascular tone and $45 \mathrm{Ca}^{2+}$ in flux in the rabbit fascial vein. Circ Res. 1992;71(2):339-45.

19. Vessières $E$, Belin de Chantemèle EJ, Guihot AL, Jardel A, Toutain B, Loufrani $L$, Henrion D. Cyclooxygenase-2-derived prostanoids reduce inward arterial remodeling induced by blood flow reduction in old obese Zucker rat mesenteric arteries. Vasc Pharmacol. 2013;58(5-6):356-62.

20. Bouvet $C$, de Chantemele EB, Guihot AL, Vessieres E, Bocquet A, Dumont $O$. Flow-induced remodeling in resistance arteries from obese Zucker rats is associated with endothelial dysfunction. Hypertension. 2007:50:248-54.

21. Pinaud F, Loufrani L, Toutain B, Lambert D, Vandekerckhove L, Henrion D, et al. In vitro protection of vascular function from oxidative stress and inflammation by pulsatility in resistance arteries. J Thorac Cardiovasc Surg. 2011;142(5):1254-62.

22. Schachner T. Pharmacologic inhibition of vein graft neointimal hyperplasia. J Thorac Cardiovasc Surg. 2006;131:1065-72. 
23. Samano N, Geijer H, Liden M, Fremes S, Bodin L, Souza D. The no-touch saphenous vein for coronary artery bypass grafting maintains a patency, after 16 years, comparable to the left internal artery: a randomized trial. J Thorac Cardiovasc Surg. 2015;150(4):880-8.

24. O'Connell TX, Sanchez M, Mowbray JF, Fonkalsrud EW. Effects on arterial intima of saline infusions. J Surg Res. 1974;16:197-203.

25. Winkler B, Reineke D, Heinisch PP, Schönhoff F, Huber C, Kadner A, et al. Graft preservation solutions in cardiovascular surgery. Interact Cardiovasc Thorac Surg. 2016;23(2):300-9.

26. Bush HL, Jakubowski JA, Curl GR, Deykin D, Nabseth DC. The natural history of endothelial structure and function in arterialized vein grafts. J Vasc Surg. 1986;3:204-15.

27. Wong CY, de Vries MR, Wang Y, van der Vorst JR, Vahrmeijer AL, Zonneveld $\mathrm{AJ}$, et al. Vascular remodeling and intimal hyperplasia in a novel murine model of arteriovenous fistula failure. J Vasc Surg. 2014:59(1):192-201.

28. Sun Q, Kawamura T, Masutani K, Peng X, Sun Q, Stolz DB, et al. Oral intake of hydrogen-rich water inhibits intimal hyperplasia in arterialized vein grafts in rats. Cardiovasc Res. 2012;94:144-53.

29. Haime H, McLean RR, Kurgansky KE, Emmert MY, Kosik N, Nelson C, et al. Relationship between intra-operative vein graft treatment with DuragraftÒ or saline and clinical outcomes after coronary artery bypass grafting. Expert rev Cardiovasc Ther. 2018;16(12):963-70.

30. Yahagi K, Kolodgie FD, Otsuka F, Finn AV, Davis HR, Joner M, et al. Pathophysiology of native coronary, vein graft, and in-stent atherosclerosis. Nat Rev Cardiol. 2015;13:79,

31. Lee MS, David EM, Makkar RR, Wilentz JR. Molecular and cellular basis of restenosis after percutaneous coronary intervention: the interwining roles of platelets, leukocytes, and the coagulation-fibrinolysis system. J Pathol. 2004; 2003(4):861-70. Review.

32. Zhang L, Peppel K, Brian L, Chien L, Freedman NJ. Vein graft neointimal hyperplasia is exarcerbated by tumor necrosis factor receptor-1 signaling in graft-intrinsic cells. Atheroscler Thromb Vasc Biol. 2004;24(10):1120-2.

33. Touyz RM, Schiffrin EL. Reactive oxygen species in vascular biology: implications in hypertension. Histochem Cell Biol. 2004;122(4):339-52.

34. Enouri S, Monteith G, Johnson R. Characteristics of myogenic reactivity in isolated rat mesenteric veins. Am J Physiol Regul Integr Comp Physiol. 2011; 300(2):R470-8

35. Thomas A. Animal models for studying vein graft failure and therapeutic interventions. Curr Opin Pharmacol. 2012;12:121-6.

36. Shukla N, Jeremy JY. Pathophysiology of saphenous vein graft failure: a brief overview of interventions. Curr Opin Pharmacol. 2012;12:114-20.

37. Goldman S, Zadina K, Moritz T. Long term patency of saphenous vein and left internal mammary artery grafts after coronary artery bypass surgery: results from a Department of Veterans Affairs Cooperative Study. J Am Coll Cardiol. 2004:44:2149-56.

38. Schachner T, Laufer $\mathrm{G}$, Bonatti J. In vivo (animal) models of vein graft disease. Eur J Cardiothorac Surg. 2006;30:451-63.

39. Wan S, Yim AP, Johnson JL, Shukla N, Angelini GD, Smith FC, et al. The endothelin 1A receptor antagonist BSF 302146 is a potent inhibitor of neointimal and medial thickening in porcine saphenous vein-carotid artery interposition grafts. J Thorac Cardiovasc Surg. 2004;127:1317-22.

\section{Publisher's Note}

Springer Nature remains neutral with regard to jurisdictional claims in published maps and institutional affiliations.

Ready to submit your research? Choose BMC and benefit from:

- fast, convenient online submission

- thorough peer review by experienced researchers in your field

- rapid publication on acceptance

- support for research data, including large and complex data types

- gold Open Access which fosters wider collaboration and increased citations

- maximum visibility for your research: over $100 \mathrm{M}$ website views per year

At $\mathrm{BMC}$, research is always in progress.

Learn more biomedcentral.com/submissions 